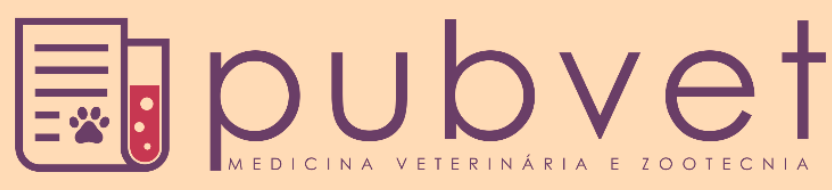

https://doi.org/10.31533/pubvet.v13n12a476.1-7

\title{
Caracterização do queijo fresco produzidos com leite de diferentes graus de estabilidade ao etanol
}

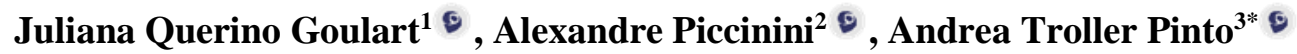 \\ ${ }^{1}$ Mestranda do Programa de Pós-Graduação em Microbiologia Agrícola e do Ambiente, Universidade Federal do Rio Grande do Sul, Instituto \\ de Ciências Básicas da Saúde, Porto Alegre, Rio Grande do Sul, Brasil \\ ${ }^{2}$ Mestrando do Programa de Pós-Graduação em Ciências Veterinárias, Universidade Federal do Rio Grande do Sul, Faculdade de \\ Veterinária, Porto Alegre, Rio Grande do Sul, Brasil \\ ${ }^{3}$ Professora do Departamento de Medicina Veterinária Preventiva, Universidade Federal do Rio Grande do Sul, Faculdade de Veterinária, \\ Porto Alegre, Rio Grande do Sul, Brasil \\ * Autor para correspondência: andrea.troller@ufrgs.br
}

Resumo. O leite instável não ácido apresenta instabilidade na presença do etanol a $72^{\circ} \mathrm{GL}$ e quantidades de ácido lático entre 0,14 e $0,18 \mathrm{~g} / 100 \mathrm{~mL}$ de leite. Este leite é descartado pela indústria causando perdas econômicas. Visando avaliar a possibilidade de uso desta matéria prima, o objetivo deste trabalho foi avaliar as características do LINA e o rendimento do queijo fresco sem sal produzido a partir dele, comparando-o com o produzido com leite normal e ácido. Para isso foram coletadas 46 amostras de leite, sendo 43,47\% LN, 32,61\% LINA e $23,92 \%$ LA. Os leites foram avaliados quanto a sua qualidade e características físico-químicas e queijos foram produzidos por coagulação enzimática. Leites ácidos tiveram menores teores de lactose, grau de estabilidade, $\mathrm{pH}$ e maior temperatura de congelamento quando comparado ao leite normal. Já o LINA apresentou estabilidade ao etanol menor que o LN e igual ao LA. A semelhança do LINA com o LN foi encontrada também nos teores de lactose, $\mathrm{pH}$ e crioscopia. Em relação aos queijos frescos sem sal produzidos, observou-se que os teores de gordura e a sinérese total foram significativamente maiores quando produzidos com LA. Não houve diferença entre os queijos produzidos quanto a rendimento, extrato seco e acidez. Com base nos resultados obtidos, pode-se afirmar que, do ponto de vista composicional, o LINA pode ser utilizado para a produção e queijos frescos, já que o rendimento dos queijos produzidos com ele não apresenta diferenças estatísticas em relação aos produzidos com LN.

Palavras chave: laticínios, leites anormais, rendimento de queijo

\section{Characterization of fresh cheese produced with milk of different degrees of ethanol stability}

Abstract. Unstable non-acid milk (LINA) has instability in the presence of ethanol at $72^{\circ}$ GL and amounts of lactic acid between 0.14 and $0.18 \mathrm{~g} / 100 \mathrm{~mL}$ milk. This milk is discarded by the industry causing economic losses. Aiming to evaluate the possibility of using this raw material, the objective of this work was to evaluate the characteristics of LINA and the yield of unsalted fresh cheese produced from it, comparing it with that produced with normal (LN) and acid milk (LA). For this, 46 milk samples were collected, being $43.47 \%$ LN, $32.61 \%$ LINA and $23.92 \%$ LA. The milks were evaluated for their quality and physicochemical characteristics and cheeses were produced by enzymatic coagulation. Acid milks had lower lactose content, degree of stability, $\mathrm{pH}$ and higher freezing temperature when compared to normal milk. LINA, on the other hand, presented ethanol stability lower than LN and equal to LA. The similarity between LINA and LN was also found in lactose, $\mathrm{pH}$ and cryoscopy levels. In relation to fresh unsalted cheese 
produced, it was observed that the fat content and total syneresis were significantly higher when produced with LA. There was no difference between the cheeses produced in yield, dry extract and acidity. Based on the results obtained, it can be stated that, from a compositional point of view, LINA can be used for the production and fresh cheese, since the yield of the cheese produced with it does not present statistical differences in relation to those produced with LN.

Keywords: dairy, abnormal milk, cheese yield

\section{Caracterización del queso fresco producido con leche de diferentes grados de estabilidad de etanol}

Resumen. La leche inestable no ácida (LINA) tiene inestabilidad en presencia de etanol a $72{ }^{\circ} \mathrm{GL}$ y cantidades de ácido láctico entre 0,14 y $0,18 \mathrm{~g} / 100 \mathrm{ml}$ de leche. Esta leche es descartada por la industria causando pérdidas económicas. Con el objetivo de evaluar la posibilidad de utilizar esta materia prima, el objetivo de este trabajo fue evaluar las características de LINA y el rendimiento de queso fresco sin sal producido a partir de él, comparándolo con el producido con leche normal (LN) y ácida (LA). Para esto, se recolectaron 46 muestras de leche, $43.47 \%$ LN, 32.61\% LINA y 23.92\% LA. Las leches fueron evaluadas por su calidad y características fisicoquímicas y los quesos fueron producidos por coagulación enzimática. Las leches ácidas tuvieron menor contenido de lactosa, grado de estabilidad, $\mathrm{pH}$ y mayor temperatura de congelación en comparación con la leche normal. LINA, por otro lado, presentó una estabilidad de etanol inferior a LN e igual a LA. La similitud entre LINA y LN también se encontró en los niveles de lactosa, $\mathrm{pH}$ y crioscopia. En relación con el queso fresco sin sal producido, se observó que el contenido de grasa y la sinéresis total fueron significativamente mayores cuando se produjeron con LA. No hubo diferencia entre los quesos producidos en rendimiento, extracto seco y acidez. Con base en los resultados obtenidos, se puede afirmar que, desde un punto de vista compositivo, LINA puede usarse para la producción de queso fresco, ya que el rendimiento del queso producido con él no presenta diferencias estadísticas en relación con los producidos con $\mathrm{LN}$.

Palabras clave: lacticinios, leche anormal, rendimiento de queso

\section{Introdução}

Os prejuízos na cadeia produtiva do leite têm levado os envolvidos a buscar alternativas para reduzir as perdas. Uma das alternativas é o aproveitamento do leite que não apresenta estabilidade em presença do etanol $72^{\circ} \mathrm{GL}$; porém, com quantidades de ácido lático dentro dos padrões de normalidade (leite instável não ácido). Atualmente a instabilidade ao álcool e conseqüentemente ao aquecimento sofrido durante os tratamentos térmicos, limita o uso deste leite, já que este pode coagular durante a pasteurização. Todavia, existem dúvidas em relação à capacidade da prova do álcool em determinar a estabilidade térmica do leite. Diversos autores apontam falhas nessa correlação, não observando coagulação do leite no teste da fervura do LINA (Andrade et al., 2014; Fischer et al., 2012; Larsen et al., 2010; Paixão et al., 2017; Pinto et al., 2006; Taffarel et al., 2015).O leite instável não ácido (LINA) é aquele que se apresenta instável (precipitação da caseína) na presença do etanol a $72^{\circ} \mathrm{GL}$ e apresenta quantidades de 0,14 a $0,18 \mathrm{~g}$ de ácido lático/100mL de leite. Alguns estudos identificaram alta prevalência do LINA no Rio Grande do Sul e grandes prejuízos gerados pela rejeição desta matériaprima pelos laticínios (Marques et al., 2007; Marx et al., 2007; Zanela et al., 2009).

A instabilidade das micelas de caseína que ocorre no LINA pode não interferir no processo produtivo dos queijos, já que para a produção dos queijos são adicionadas enzimas proteolíticas responsáveis pela formação do coágulo. Neste caso, o uso do LINA para a produção de queijos frescos pode ser uma alternativa viável. Todavia, ainda não se sabe ao certo os efeitos do LINA na fabricação de queijos maturados. 
Visando avaliar os potenciais usos do LINA, este estudo teve por objetivo avaliar o rendimento do queijo fresco sem sal com ele produzido, comparando-o com o produzido com leite normal (LN) e ácido (LA).

\section{Material e métodos}

Foram coletadas 46 amostras de leite cru refrigerado com quantidades de ácido lático superiores a $0,14 \mathrm{~g} / 100 \mathrm{~mL}$ de leite de tanques isotérmicos de caminhões, diretamente na plataforma de recebimento da indústria. As alíquotas coletadas correspondiam a $1500 \mathrm{~mL}$ e as amostras foram acondicionadas em frascos estéreis e mantidas em temperaturas inferiores a $10^{\circ} \mathrm{C}$ até a chegada ao laboratório.

As análises físico-químicas, contagem de células somáticas e contagem bacteriana total das amostras de leite cru refrigerado: As amostras foram avaliadas quanto aos percentuais de proteína, lactose, gordura, estrato seco total e estrato seco desengordurado; índice crioscópico, estabilidade ao etanol e acidez titulável. Esses dois últimos parâmetros permitiram a classificação das amostras de leite como leite normal (estabilidade ao etanol $\geqq 72^{\circ} \mathrm{GL}$ e acidez entre 0,14 e $0,18 \mathrm{~g} / 100 \mathrm{~mL}$ ); leite instável não ácido (estabilidade $<72^{\circ} \mathrm{GL}$ e acidez entre 0,14 e $0,18 \mathrm{~g} / 100 \mathrm{~mL}$ ) e leite ácido (acidez $>0,18 \mathrm{~g} / 100 \mathrm{~mL}$ ) (Stumpf et al., 2013). Além disso, foram avaliadas as contagens de células somáticas e contagens bacterianas totais por infravermelho e citometria de fluxo, respectivamente. Todas as análises foram realizadas em triplicata.

A produção de queijo fresco sem sal com leites normais (LN), leites instáveis não ácidos (LINA) e leites ácidos (LA) foi feita a partir de alíquotas de um litro de leite. As mesmas foram armazenadas por 12 horas a $4 \pm 1^{\circ} \mathrm{C}$. Após este período, o leite sofreu pasteurização lenta, sendo submetido a temperatura de $65 \pm 1^{\circ} \mathrm{C}$ por 30 minutos e resfriado a $38 \pm 1^{\circ} \mathrm{C}$ quando foi adicionado $0,2 \mathrm{~g}$ de cloreto de cálcio dissolvido em água. Após a homogeneização foi adicionado coagulante (quimosina com poder coagulante de $75 \mathrm{IMCU}$ ) diluída em água na proporção de 1/10 e a mistura foi deixada em banho-maria a $36 \pm 1^{\circ} \mathrm{C}$ por 40 minutos. Em seguida a massa resultante da coagulação enzimática do leite foi cortada e agitada por 10 minutos para promover a separação do soro. O conteúdo foi vertido em uma forma para queijos e foi mensurada a quantidade de soro de leite resultante do processo produtivo. Os queijos foram armazenados em refrigeração a $4 \pm 1^{\circ} \mathrm{C}$ por 24 e 48 horas, após estes períodos, foram virados e as quantidades residuais de soro foram mensuradas. Finalizado este processo, os queijos foram pesados e calculados seus rendimentos.

A caracterização físico-química dos queijos frescos sem sal produzidos com leite normal, leite instável não ácido e leite ácido foi feita pela determinação de sólidos totais, gordura, umidade e ácido lático nos queijos frescos sem sal produzidos conforme Brasil (2006). As análises físico-químicas dos queijos produzidos foram realizadas em triplicata.

Os resultados analíticos foram analisados estatisticamente, sendo que as amostras de leite foram agrupadas em três categorias, conforme estabelecido anteriormente. As médias dos resultados obtidos das análises de leite cru e queijos frescos sem sal produzidos foram comparadas entre as categorias. Os resultados foram submetidos à análise de variância (ANOVA) e teste de Tukey $(\mathrm{P}<0,05)$.

\section{Resultados e discussão}

As 46 amostras de leite cru refrigerado foram coletadas e categorizadas de acordo com a estabilidade ao álcool e acidez em gramas de ácido lático, sendo 43,47\% (20/46) consideradas leite normal (LN), $32,61 \%$ (15/46) leite instável não ácido (LINA) e 23,92\% (11/46) de leite ácido (LA). A prevalência de leite instável não ácido foi, portanto, de 32,61\%. Estudos anteriores obtiveram como resultados prevalências que variaram de $29 \%$ a $58 \%$, sendo evidentes as variações de acordo com as estações do ano, período de lactação dos animais, estado nutricional do rebanho etc (Barbosa et al., 2012; Ciprandi et al., 2012; Zanela et al., 2009). A caracterização do leite utilizado na produção dos queijos está apresentada na tabela 1 .

As médias das amostras testadas se apresentam em conformidade com a Instrução Normativa n $76 / 2018$, com exceção do estrato seco desengordurado das amostras de LA, que se apresentavam abaixo do especificado nesta legislação. Os teores de lactose também apresentaram valores médios menores aos que são especificados pela legislação, independente da categoria em que se enquadravam 
as amostras. Estudo realizado por Oliveira et al. (2011), também observado, como resultados,

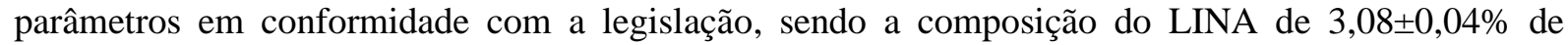

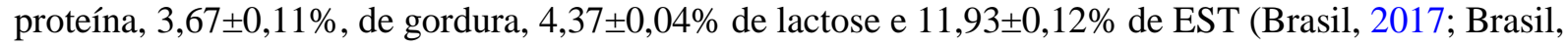
2018).

Tabela 1. Médias e desvios padrão dos resultados obtidos para os percentuais de proteína, lactose, gordura, estrato seco desengordurado e estrato seco total, além da estabilidade ao álcool, temperatura de congelamento, acidez titulável, $\mathrm{pH}$, contagem de células somáticas e contagem bacteriana total do leite cru caracterizado como normal (LN), instável não ácido (LINA) e ácido (LA) e os valores previstos em legislação.

\begin{tabular}{|l|c|c|c|c|}
\hline Parâmetro avaliado & LN & LINA & LA & Legislação $^{1}$ \\
\hline \% Proteína & $3,23+0,11$ & $3,24+0,09$ & $3,19+0,06$ & Min. $2,9 \%$ \\
\hline$\%$ Lactose & $4,29+0,09^{\mathrm{a}}$ & $4,22+0,10^{\mathrm{ab}}$ & $4,12+0,12^{\mathrm{b}}$ & Min. $4,6 \%$ \\
\hline \% Gordura & $3,74+0,23$ & $3,79+0,21$ & $3,79+0,17$ & Min. $3,0 \%$ \\
\hline$\%$ EST & $12,32+0,34$ & $12,27+0,28$ & $12,16+0,21$ & Min. $11,4 \%$ \\
\hline$\%$ ESD & $8,58+0,11$ & $8,48+0,07$ & $8,37+0,04$ & Min. $8,4 \%$ \\
\hline Estabilidade ao Etanol ${ }^{2}$ & $74,90+1,84^{\mathrm{a}}$ & $64,13+3,22^{\mathrm{b}}$ & $62,36+1,15^{\mathrm{b}}$ & $>72^{\circ} \mathrm{GL}$ \\
\hline Acidez & $0,15+0,0066^{\mathrm{a}}$ & $0,16+0,0073^{\mathrm{b}}$ & $0,19+0,0153^{\mathrm{c}}$ & $0,14-0,18$ \\
\hline pH & $6,84+0,07^{\mathrm{a}}$ & $6,78+0,12^{\mathrm{a}}$ & $6,60+0,14^{\mathrm{b}}$ & - \\
\hline Temperatura de congelamento $\left({ }^{\circ} \mathrm{H}\right)$ & $-0,534+0,006^{\mathrm{a}}$ & $-0,535+0,006^{\mathrm{a}}$ & $-0,543+0,006^{\mathrm{b}}$ & $-0,555 \mathrm{a}-0,530$ \\
\hline CCS (Células/mL) & $8,90 \times 10^{5}$ & $8,79 \times 10^{5}$ & $7,90 \times 10^{5}$ & $5,00 \mathrm{x} 10^{5}$ \\
\hline CBT (UFC/mL) & $6,66 \times 10^{6 \mathrm{a}}$ & $1,00 \times 10^{7 \mathrm{~b}}$ & $9,94 \times 10^{6 \mathrm{~b}}$ & $3,00 \mathrm{x} 10^{5}$ \\
\hline
\end{tabular}

Médias seguidas pela mesma letra, na mesma linha, não diferem entre si $(\mathrm{P}<0,05) .{ }^{1}$ valores normais definidos pela legislação brasileira. ${ }^{2}$ menor graduação alcoólica em que o leite apresentou estabilidade. ${ }^{3}$ expresso em g de ácido lático/100 mL

Os leites das diferentes categorias (LN, LINA e LA) não apresentaram diferenças quanto a sua composição ( $\mathrm{P}<0,05)$, a exceção do percentual de lactose, em que o LA apresentou percentual significativamente menor em relação ao LINA e ao LN. Estudo realizado por Marx et al. (2007), onde foram comparadas as composições dos LN e LINA, não foram observadas diferenças significativas nos teores de gordura, proteínas, lactose, EST, ESD. Marques et al. (2007) observaram que os teores de lactose eram menores no LINA. Zanela et al. (2009) concluíram que o LINA tem menores teores dos componentes proteína bruta, lactose, sólidos desengordurados e sólidos totais. Os menores teores de lactose encontrados no LA provavelmente devem-se à transformação da lactose em ácido lático, o que resultou em leites mais ácidos. A partir de uma molécula de lactose, quatro moléculas de ácido láctico são formadas, e consequentemente o $\mathrm{pH}$ diminui podendo causar a precipitação da caseína (Caprita et al., 2003; Zanela et al., 2006).

O grau de estabilidade ao álcool, em média, foi significativamente maior nos LN. Os resultados das médias da acidez foram significativamente inferiores nos LN e superiores nos LA. Já o índice crioscópico foi significativamente menor no LA. A conversão de lactose em ácido lático e a redução do pH afeta a estabilidade da caseína, provocando a coagulação do leite quando submetido a elevadas graduações de álcool. Isto pode ser observado no LA, onde valores elevados de acidez estão associados a instabilidades a graduações inferiores a $72^{\circ} \mathrm{GL}$ do álcool. Estudos anteriores que compararam o índice crioscópico do LINA e o LN observaram pontos de congelamento que variaram entre $-0,546^{\circ} \mathrm{H} \mathrm{e}$ $0,531^{\circ} \mathrm{H}$. A variação pode estar relacionada aos teores de lactose e à acidez dos leites avaliados, sendo os menores índices crioscópicos em leites com maiores teores de lactose e menores quantidades de ácido lático em sua composição (Caprita et al., 2003; Marques et al., 2007; Marx et al., 2007).

A qualidade do leite quanto à contagem de células somáticas e contagem bacteriana total dos leites coletados também está apresentada na tabela 1. Não foram encontradas diferenças significativas na média da CCS das diferentes categorias do leite estudado (LN, LINA e LA). Já a média da CBT foi significativamente maior no LINA e no LA. Em estudo realizado por Marx et al. (2007), que compararam CCS do LN e LINA, também não observou diferenças estatísticas. Em compensação, Marques et al. (2007) encontraram diferenças significativas na CCS para LN e LINA, sendo a contagem significativamente menor no $\mathrm{LN}$. 
As análises físico-químicas dos queijos frescos sem sal produzidos com LN, LINA e LA foram avaliadas quanto à expulsão de soro e sua composição, conforme apresentado na tabela 2.

Tabela 2. Caracterização física e química, rendimento e sinérese dos QMF produzidos com leite cru caracterizado como normal (LN), instável não ácido (LINA) e ácido (LA)

\begin{tabular}{|c|c|c|c|}
\hline & $\mathrm{LN}$ & LINA & LA \\
\hline$\overline{\mathrm{pH}}$ & $7,12+0,12^{\mathrm{a}}$ & $7,04+0,09^{\mathrm{ab}}$ & $7,00+0,11^{\mathrm{b}}$ \\
\hline Acidez \% & $0,024+0,007$ & $0,027+0,011$ & $0,027+0,006$ \\
\hline Gordura \% & $17,43+1,54^{\mathrm{a}}$ & $18,36+1,33^{\mathrm{ab}}$ & $19,39+2,17^{b}$ \\
\hline Umidade & $62,91+2,44$ & $61,08+2,24$ & $61,99+5,49$ \\
\hline Matéria Seca & $37,09+2,44$ & $38,92+2,24$ & $38,00+5,49$ \\
\hline Rendimento (L/Kg) & $5,50+0,51$ & $5,62+0,40$ & $5,56+0,30$ \\
\hline Gordura no extrato seco & $47,06+3,77^{\mathrm{a}}$ & $47,30+3,73^{\mathrm{ab}}$ & $51,77+7,63^{\mathrm{b}}$ \\
\hline Sinérese no dia 0 & $669,00+38,39$ & $677,33+38,51$ & $700,90+54,89$ \\
\hline Sinérese no dia 1 & $87,75+23,80$ & $87,27+21,16$ & $89,10+25,56$ \\
\hline Sinérese no dia 2 & $5,43+3,96$ & $6,20+3,49$ & $4,38+3,05$ \\
\hline Sinérese Total & $762,18+22,80^{a}$ & $770,81+22,52^{\mathrm{ab}}$ & $794,40+29,55^{\mathrm{b}}$ \\
\hline
\end{tabular}

Médias seguidas pela mesma letra, na mesma linha, não diferem entre si $(\mathrm{P}<0,05)$.

Os resultados dos parâmetros físico-químicos dos queijos produzidos com LN e LINA não diferiram entre si. Porém, observou-se que os teores de gordura e a sinérese total foram significativamente maiores nos queijos frescos sem sal produzidos com LA. Estudo semelhante, mas com queijo produzido com leite cru, revelaram características como 68,20\% de umidade, 22,35\% de gordura e pH de 6,2 (Gomes et al., 2011). Os resultados conflitantes podem ser relativos a maior acidificação do queijo de leite cru, pela não destruição de bactérias láticas normais do leite.

Os maiores teores de gordura no queijo fresco sem sal produzido com LA podem estar relacionados a não padronização do leite que foi utilizado como matéria-prima. Alves et al. (2011) mencionam, em seu estudo, que os teores de gordura do leite não padronizado podem ter influenciado nos maiores teores de gordura do queijo. Porém, no presente estudo, os teores de gordura do LA não foram significativamente diferentes do LN e LINA.

Houve maior sinérese $(\mathrm{P}<0,05)$ em queijos produzidos com LA. Maiores quantidades de ácido lático no leite promovem maior desestabilização das moléculas de caseína, as tornando menos resistentes. Assim, reduz-se a retenção de água pela rede de caseína formada e ocorre a perda deste componente do soro (Walstra, 1999).

O rendimento dos queijos frescos sem sal produzidos com LINA e LN é semelhante, o que pode ser um indicativo que o LINA pode ser utilizado pela indústria, evitando o descarte deste leite. A utilização de testes como o álcool-alizarol, onde a alizarina indica níveis elevados de acidez poderiam auxiliar na decisão de transportar ou não tal matéria-prima. Leites que se apresentam coagulados sem indícios de acidez elevada poderiam ser transportados em tanques próprios, sem contato com os LN, tendo destino apropriado. Estudos aprofundados com a utilização do LINA em outros produtos lácteos são necessários para se averiguar as possibilidades de utilização desta matéria-prima.

\section{Conclusão}

O queijo produzido com LINA teve rendimento semelhante com aquele produzido com o LN. O LINA pode ser utilizado na fabricação do queijo fresco sem sal sem prejuízo ao rendimento e a composição do produto. Estudos posteriores referentes à qualidade microbiológica dos queijos frescos sem sal devem ser realizados para verificar a inocuidade destes produtos.

\section{Referências bibliográficas}

Alves, C. C. C., Gemal, N. D. H., Cortez, M. A. S., Franco, R. M. \& Mano, S. B. (2011). Utilização de Lactobacillus acidophilus e de acidificação direta na fabricação de queijo de minas frescal. Arquivo 
Brasileiro de Medicina Veterinária e Zootecnia, 63(6):1559-1566. doi: http://dx.doi.org/10.1590/S0102-09352011000600038.

Andrade, K. D., Rangel, A. H. N., Araújo, V. M., Medeiros, H. R., Bezerra, K. C., Bezerril, R. F. \& Lima Júnior, D. M. (2014). Qualidade do leite bovino nas diferentes estações do ano no estado do Rio Grande do Norte. Revista Brasileira de Ciência Veterinária, 21(3):213-216.

Barbosa, R. S., Fischer, V., Ribeiro, M. E. R., Zanela, M. B., Sutmpf, M. T., Kolling, G. J., . . Egito, A. S. (2012). Caracterização eletroforética de proteínas e estabilidade do leite em vacas submetidas à restrição alimentar. Pesquisa Agropecuária Brasileira, 47(4):621-628. doi: http://dx.doi.org/10.1590/S0100-204X2012000400019.

Brasil. Ministério da Agricultura Pecuária e Abastecimento. Instrução Normativa $n^{\circ}$ 68, de 12 de dezembro de 2006. Estabelece Métodos Analíticos Oficiais Físico-Químicos - Produtos Lácteos. Diário Oficial da República Federativa do Brasil, Brasília, 2006.

Brasil. Ministério da Agricultura Pecuária e Abastecimento. Decreto n 9.013, de 29 de março de 2017. Regulamento da inspeção industrial e sanitária de produtos de origem animalRIISPOA. Diário Oficial da República Federativa do Brasil, Brasília, 2017.

Brasil. Ministério da Agricultura Pecuária e Abastecimento. Instrução Normativa ${ }^{\circ} 76$ de 26 de novembro de 2018. Aprova o Regulamento Técnico de Identidade e Qualidade de Leite Cru Refrigerado, o Regulamento Técnico de Identidade e Qualidade de Leite Pasteurizado e o Regulamento Técnico de Identidade e Qualidade do Leite tipo A. Diário Oficial da República Federativa do Brasil, Brasília, 2018.

Caprita, R., Caprita, A. \& Benscik, I. (2003). The electric conductivity as parameter for milk quality appreciation. Acta Veterinaria Scandinavica, 44(1):264. doi: http://dx.doi.org/10.1186/1751-014744-S1-P872003.

Ciprandi, A., Pereira, B. P. \& Pinto, A. T. (2012). Ocorrência de leite instável não ácido (LINA) em uma usina de beneficiamento da região metropolitana de Porto Alegre/RS. Veterinária em Foco, 9(2):128-133.

Fischer, V., Ribeiro, M. E. R., Zanela, M. B., Marques, L. T., de Abreu, A. S., Machado, S. C., . . . Stumpf, M. T. (2012). Leite instável não ácido: um problema solucionável? Revista Brasileira de Saúde e Produção Animal, 13(3):838-849.

Gomes, A. P., Cruz, A. G., Cadena, R. S., Celeghini, R. M. S., Faria, J. A. F., Bolini, H. M. A., . . Granato, D. (2011). Manufacture of low-sodium minas fresh cheese: Effect of the partial replacement of sodium chloride with potassium chloride. Journal of Dairy Science, 94(6):2701-2706. doi: https://doi.org/10.3168/jds.2010-3774.

Larsen, M. K., Nielsen, J. H., Butler, G., Leifert, C., Slots, T., Kristiansen, G. H. \& Gustafsson, A. H. (2010). Milk quality as affected by feeding regimens in a country with climatic variation. Journal of Dairy Science, 93(7):2863-2873. doi: https://doi.org/10.3168/jds.2009-2953.

Marques, L. T., Zanela, M. B., Ribeiro, M. E. R., Stumpf Junior, W. \& Fischer, V. (2007). Ocorrência do leite instável ao álcool $76 \%$ e não ácido (LINA) e efeito sobre os aspectos físico-químicos do leite. Revista Brasileira Agrociência, 13(1):91-97. doi: http://dx.doi.org/10.18539/cast.v13I1.1343.

Marx, I. G., Lazzarotto, T. C., Drunkler, D. A. \& Colla, E. (2007). Ocorrência de leite instável não ácido na região Oeste do Paraná. Revista Ciências Exatas e Naturais, 13(1):101-112.

Oliveira, C. A. F., Lopes, L. C., Franco, R. C. \& Corassin, C. H. (2011). Composição e características físico-químicas do leite instável não ácido recebido em laticínio do Estado de São Paulo, Brasil. Revista Brasileira de Saúde e Produção Animal, 12(2):508-515.

Paixão, M. G., Lopes, M. A., Costa, G. M., Souza, G. N., Abreu, L. R. \& Pinto, S. M. (2017). Milk quality and financial management at different scales of production on dairy farms located in the south of Minas Gerais state, Brazil. Revista Ceres, 64(3):213-221. doi: http://dix.doi.org/10.1590/0034737X201764030001. 
Pinto, C. L. O., Martins, M. L. \& Vanetti, M. C. D. (2006). Qualidade microbiológica de leite cru refrigerado e isolamento de bactérias psicrotróficas proteolíticas1. Ciência e Tecnologia de Alimentos, 26(3):645-651.

Stumpf, M. T., Fischer, V., McManus, C. M., Kolling, G. J., Zanela, M. B., Santos, C. S., . . Montagner, P. (2013). Severe feed restriction increases permeability of mammary gland cell tight junctions and reduces ethanol stability of milk. Animal, 7(7):1137-1142. doi: http://doi.org/10.1017/S1751731113000128.

Taffarel, L. E., Costa, P. B., Tsutsumi, C. Y., Klosowski, E. S., Portugal, E. F. \& Lins, A. C. (2015). Variação da composição e qualidade do leite em função do volume de produção, período do ano e sistemas de ordenha e de resfriamento. Semina: Ciências Agrárias, 36(3-Supl-1):2287-2300.

Walstra, P. (1999). Dairy technology: principles of milk properties and processes. New York, USA: CRC Press.

Zanela, M. B., Fischer, V., Ribeiro, M. E. R., Barbosa, R. S., Marques, L. T., Stumpf Junior., W. \& Zanela, C. (2006). Leite instável não-ácido e composição do leite de vacas Jersey sob restrição alimentar. Pesquisa Agropecuária Brasileira, 41(5):835-840.

Zanela, M. B., Ribeiro, M. E. R., Fischer, V., Gomes, J. F. \& Stumpf Junior, W. (2009). Ocorrência do leite instável não ácido no noroeste do Rio Grande do Sul. Arquivo Brasileiro de Medicina Veterinária e Zootecnia, 61(4):1009-1013.

Recebido: 2 de setembro, 2019

Aprovado: 7 de novembro, 2019.

Publicado: 25 de janeiro, 2020

Licenciamento: Este artigo é publicado na modalidade Acesso Aberto sob a licença Creative Commons Atribuição 4.0 (CC-BY 4.0), a qual permite uso irrestrito, distribuição, reprodução em qualquer meio, desde que o autor e a fonte sejam devidamente creditados. 